\title{
Isolation and Characterization of Lignin from Tropical and Temperate Hardwood
}

\author{
M. Sarwar Jahan ${ }^{a *}$ and Sung Phil Mun ${ }^{\mathrm{b}}$ \\ ${ }^{a}$ Pulp and Paper Research Division, BCSIR Laboratories, Dhaka, Dhaka-1205, Bangladesh and ${ }^{b}$ College of \\ Agriculture and Life Science, Chonbuk National University, Jeonju, Jeonbuk, 561-756, Korea.
}

\begin{abstract}
Dioxane and milled wood lignins (MWL) were isolated from tropical hardwood, Nalita (Trema orientalis) and temperate hardwood, aspen. These lignins were characterized by UV, FTIR, ${ }^{1} \mathrm{H}-\mathrm{NMR}$ and ${ }^{13} \mathrm{C}-\mathrm{NMR}$ spectroscopy, alkaline nitrobenzene oxidation, molecular weight determination, elemental and methoxyl analysis. The structural analysis revealed that Nalita and aspen lignin is syringyl-guaiacyl type. Aspen lignin had higher syringyl unit than Nalita lignin. The $\beta$-O-4 type linkages are the main interunit linkages and more abundant in aspen than Nalita. Dioxane lignin showed higher free phenolic hydroxyl group than MWL in both species. The weight average molecular weight of aspen lignin was lower than that of Nalita lignin. Nalita and aspen lignins contained both erythro and threo configuration, but erythro proton gave stronger peak. A UV absorption maximum of aspen lignin was at $274 \mathrm{~nm}$, whereas it was shifted to $280 \mathrm{~nm}$ for Nalita lignin.
\end{abstract}

Keyword: Trema orientalis, Aspen, Dioxane lignin, Milled wood lignin, Syringyl-guaiacyl, $\beta$-O-4 linkages,

\section{Introduction}

Lignin is the second most abundant biopolymer. Lignin performs multiple functions essential for the life of vascular plants. It provides mechanical strength and structural support, particularly in the case of trees, to the growing plant. Lignin prevents the permeation of water across the cell wall, thus facilitating vertical conduction of water, nutrients and metabolites in the xylem tissue. It is formed in the cell wall of vascular plants through oxidative coupling of 4-hydroxyphenylpropanoid compounds. The structure and biosynthetic pathway of lignin have been studied for more than a century; however, its structure and biosynthesis pathway have not yet been completely elucidated (Boerjan et al. 2003; Ralph et al. 2004; Wu and Argyropoulos 2003). A primary problem in elucidating the structure of native lignin is that it cannot be isolated in a chemically unaltered form. Early lignin preparation techniques used strong mineral acids to reach high lignin yields (Adler 1977). Such drastic conditions, however, were found to cause irreversible reactions that severely alter the structure of the isolated material. Björkman (1954) advanced first towards isolating lignin in a relatively unaltered state. He extracted lignin from finely ball-milled wood with aqueous dioxane. This is the most used techniques of isolating lignin from wood in a chemically unaltered form (Chang et al. 1975). This lignin is called

\footnotetext{
* Corresponding author: E-mail: sarwar2065@yahoo.co.uk
}

milled wood lignin (MWL). The yield in MWL from hardwood was poor, but higher lignin yield was obtained by acidic dioxane method (Evtuguin et al. 2001). Tropical hardwood shows poor pulpability and bleachability as compared to temperate hardwood. Certainly this is due to structural differences of these species (Jahan and Mun 2006, 2007).

In Bangladesh, one of the fastest growing woods is Trema orientalis (Nalita). It is a potential fibrous resource for pulping in tropical region (Jahan and Mun 2003, 2004). In this work, we isolated lignin by milled wood lignin (MWL) and acidic dioxane method from Nalita a tropical hardwood and a temperate hardwood. The isolated lignin was characterized with regard to elemental and methoxyl analysis, alkaline nitrobenzene oxidation, molecular weight determination and spectroscopic analysis.

\section{Materials and Methods}

\section{Raw materials}

The small piece of Nalita and aspen wood were ground (40/60 mesh) in a Wiley mill, extracted with alcohol-benzene solvent and dried in vacuum over $\mathrm{P}_{2} \mathrm{O}_{5}$. 


\section{Isolation of lignin}

\section{Preparation of milled wood lignin (MWL)}

Following the Bjorkman the extracted wood meal was ground in a vibratory ball mill for $100 \mathrm{~h}$. The milling proceeded for $12 \mathrm{~h}$ per day. Milled wood was mixed with dioxane (9:1) and extracted inside vibratory ball mill for $24 \mathrm{~h}$. The solution was centrifuged and supernatant was evaporated to dryness under reduced pressure. The residue was dissolved in acetic acid: water (9:1) and the solution was then added drop wise by small needle dropper to water with constant stirring. A precipitate was formed. The solution was centrifuged and residue was dried in vacuum over $\mathrm{P}_{2} \mathrm{O}_{5}$. The dried residue was dispersed in 1, 2 dichlorethane: ethanol (2:1), which was then centrifuged. The clear supernatant was added dropwise to anhydrous diethyl ether and a precipitate was formed, which was centrifuged and residue was dried in vacuum over $\mathrm{P}_{2} \mathrm{O}_{5}$. The yield of MWL was calculated based on Klason lignin contents in wood.

\section{Dioxane lignin}

The alcohol-benzene extract free wood meals were refluxed with acidic dioxane (9:1) solution. The concentration of $\mathrm{HCl}$ in dioxane solution was $0.2 \mathrm{~N}$. The dioxane to wood meal ratio was 8:1. The wood meal was refluxed with dioxane solution for about 1 hour in $\mathrm{N}_{2}$ atm. The $\mathrm{N}_{2}$ flow was maintained at $50 \mathrm{~mm} / \mathrm{min}$. After completing reflux time, wood meal dioxane mixture was filtered in a Buckner funnel. The residue was washed with dioxane solution (9:1). The dioxane solution was then neutralized by adding solid $\mathrm{Na}_{2} \mathrm{CO}_{3}$ and filtered. The filtrate was concentrated in vacuum evaporator at $40^{\circ} \mathrm{C}$. Then conc. dioxane soln. was added drop wise to water to precipitate lignin. The lignin precipitate was washed and dried in vacuum over $\mathrm{P}_{2} \mathrm{O}_{5}$.

Dried crude lignin was dissolved in dioxane (9:1), and again precipitated in ether with constant stirring with a magnetic bar. The precipitated pure lignin was dried in vacuum over $\mathrm{P}_{2} \mathrm{O}_{5}$ and weighed. The yield of dioxane lignin was calculated based on Klason lignin. The purity of MWL and dioxane lignin was determined by measuring Klason lignin. The carbohydrates content of isolated lignin were determined by Tappi test method (T $249 \mathrm{~cm} \mathrm{00).}$

\section{Acetylation}

Isolated MWL or dioxane lignin (100 mg) was added in 1.5 $\mathrm{ml}$ of dry pyridine- acetic anhydride (1:1) and kept for $72 \mathrm{~h}$.
The solution was added to a 10 -fold volume of ice-cold water whereupon the acetylated sample was recovered as a precipitate, which was purified by successive washing with water and dried under vacuum over $\mathrm{P}_{2} \mathrm{O}_{5}$.

\section{Elemental analysis}

$\mathrm{C}, \mathrm{H}, \mathrm{O}$ and $\mathrm{N}$ analyses of lignin were carried out in analytical centre, Kyushu University, Japan. The methoxyl content in dioxane lignin was determined in accordance to Japan International Standard Methods (JIS P8013 1972).

\section{Spectroscopy}

Ultraviolet: 7-8 mg lignin was dissolved in $100 \mathrm{ml}$ dioxane (9:1) followed by two times dilution. Then spectra were recorded using Hewlett Packard 8452A spectrophotometer.

FTIR: IR spectra were recorded by using a Shimadzu FTIR spectrometer model 8201PC. The dried samples were embedded in $\mathrm{KBr}$ pellets in the concentration of about 1mg/ $100 \mathrm{mg} \mathrm{KBr}$. The spectra were recorded in the absorption band mode in the range 4000-400 $\mathrm{cm}^{-1}$.

${ }^{1} \mathrm{H}$ NMR: Spectra were recorded for solutions of $100 \mathrm{mg}$ of acetylated lignin contained in $0.5 \mathrm{ml} \mathrm{CDCl}_{3}$, using tetramethylsilane (TMS) as internal standard in a JEOL JNM-EX 400 spectrometer. For quantification of protons, the signal in specified regions of the spectrum were integrated with respect to a spectrum-wide baseline drawn at the level of the background noise, and the results were referred to the signal for methoxyl protons, whose average number per $\mathrm{C}_{9}$ unit was established as described above.

${ }^{13} \mathrm{C}$ NMR: $100 \mathrm{mg}$ of acetylated lignins was dissolved in 0.5 $\mathrm{ml} \mathrm{CDCl}_{3}$ and spectra were recorded at $100 \mathrm{MHz}$ in a JEOL JNM-EX 400 spectrometer with TMS as internal standard. A minimum of 10,000 scans was collected for each sample.

\section{Alkaline nitrobenzene oxidation}

Alkaline nitrobenzene oxidation of Nalita and aspen MWL and dioxane lignin was carried out according to Mun's modified method (Mun and Wi 1991). GC analysis was conducted using a Shimatzu GC 17A gas chromotograph equipped with Neutrabond 1 capillary column (30 m x 0.53 mm). Conditions used were as follows: column temperature was programmed to increase from 150 to $250^{\circ} \mathrm{C}$ at the rate of $5^{\mathrm{O}} \mathrm{C} / \mathrm{min}$; injection and detection temperature were 220 and $250^{\circ} \mathrm{C}$, respectively; column flow rate was $6 \mathrm{ml} / \mathrm{min}$ and split ratio 30 . 


\section{Molecular weight}

The weight average (Mw) and number average molecular (Mn) weight of Nalita and aspen acetylated lignins were determined by GPC on a Sodex KF-802.5 column. The samples were dissolved in tetrahydrofuran (THF) and $10 \mu \mathrm{l}$ was injected. The column was operated at $30{ }^{\mathrm{O}} \mathrm{C}$ and eluted with $\mathrm{THF}$ at a flow rate of $1 \mathrm{ml} / \mathrm{min}$. The column was calibrated using polystyrene standards.

\section{Results and Discussion}

\section{Yield}

The extractable yields of MWL and dioxane lignin are given in Table I. The yield of MWL in Nalita wood was $23.8 \%$ while the yield of dioxane lignin $43.8 \%$ based on klason lignin. The purity of these lignins was higher than $80 \%$ (Table I). The yield of dioxane lignin (37.3\%) from aspen was lower than Nalita lignin. This could be rationalized on the basis that, acidic degradation of lignin might occur at higher acid concentration, resulting in actual delignification and the generation of low molecular weight lignin derivatives (Lundquist 1976) which are not recovered during lignin isolation procedure. The yield in Nalita milled wood lignin (MWL) was lower than that of aspen MWL. The acidic isolation conditions employed for the lignin extraction process are believed to result in the hydrolysis of lignin-carbohydrate complex (LCC) linkages allowing the release of lignin fragments into the aqueous dioxane solution from Nalita wood (Gellerstedt et al. 1994). The carbohydrates content was about $3 \%$ for MWL and $5 \%$ for dioxane lignin. It is observed that the yields of enzymatic mild acidolysis lignin were found to be greater than those of the corresponding MWL, regardless of the wood species from which they were isolated (Guerra et al. 2006). Overall the yield of extractable MWL of temperate hardwood was better than tropical hardwood. Such low yield in MWL was not totally surprising, however, when viewed in light of the recent conclusions of Hu et al. (Hu et al 2006) and Fujimoto et al. (Fugimoto et al. 2005), where the extent of extractable MWL was shown to be dependent upon milling severity. To isolate MWL in higher yields, more extensive milling is required (Ikeda et al. 2002).

\section{Table I. Yields of lignin}

\begin{tabular}{l|c|c|c|c}
\hline \multirow{2}{*}{ Sample } & \multicolumn{2}{|c|}{ MWL } & \multicolumn{2}{c}{ Dioxane } \\
\cline { 2 - 5 } & Yield, \% & Purity, \% & Yield, \% & Purity, \% \\
\hline Nalita & 23.8 & 81.3 & 45.0 & 80.0 \\
Aspen & 43.8 & 83.1 & 37.3 & 81.4 \\
\hline
\end{tabular}

\section{Ultraviolet spectra}

Fig. 1 shows that Nalita lignin had well defined maxima at $280 \mathrm{~nm}$, while aspen lignin had $274 \mathrm{~nm}$ in both MWL and dioxane lignin. This fact contributes to the higher symmetry of the phenylpropane units in aspen lignin caused by the higher syringyl units. It is known that guaiacyl compounds exhibit maxima in the region of $280 \mathrm{~nm}$. However, the substitutions of an extra methoxyl group in the 5-position shift the maxima to lower wavelength. Absorptivities of Nalita and aspen MWL was almost similar $\left(15 \mathrm{Lg}^{-1} \mathrm{~cm}^{-1}\right)$, but aspen dioxane lignin was higher than Nalita as shown in Table II. Normally temperate zone hardwood lignins show absorption coefficient as high as 16 (Sarkanen et al 1967; Goldschmid 1971). The shoulder at $310-320 \mathrm{~nm}$ in Nalita lignin revealed that the presence of ester or ether bonds between hydroxycinnamic acids such as $p$-cumaric acid and ferulic acid of lignin (Higuchi et al 1967).
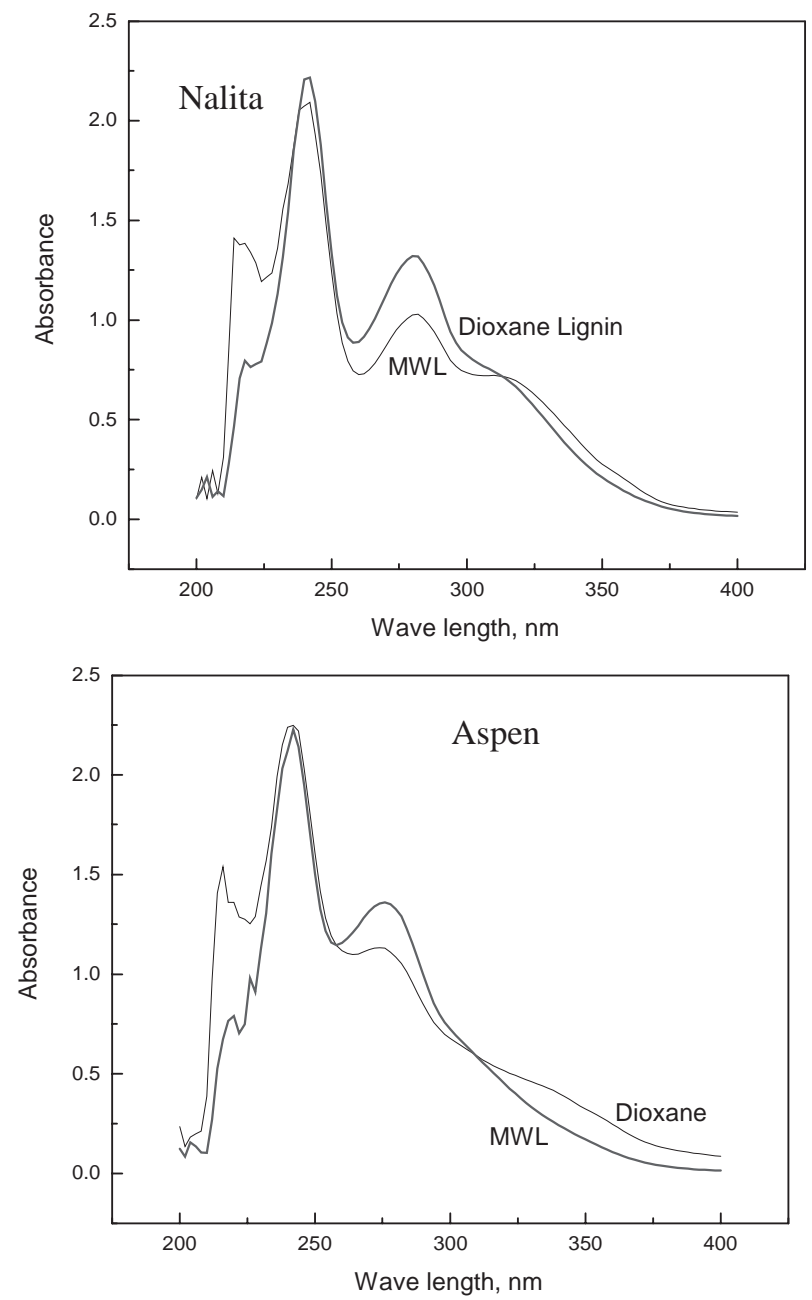

Fig. 1. UV spectra of MWL and dioxane lignin from Nalita and Aspen 
Table II. UV absorption of dioxane

\begin{tabular}{l|c|c|c|c}
\hline \multirow{2}{*}{ ignin } & \multicolumn{2}{|c|}{$\begin{array}{c}\text { Wave length } \\
\text { at max. nm }\end{array}$} & \multicolumn{2}{c}{$\begin{array}{c}\text { Absorptivity at } \\
\text { max }\left(\mathrm{Lg}^{-1} \mathrm{~cm}^{-1}\right)\end{array}$} \\
\cline { 2 - 5 } & MWL & Dioxane & MWL & Dioxane \\
\hline Nalita & 280 & 280 & 15.00 & 12.53 \\
Aspen & 274 & 274 & 15.78 & 14.17 \\
\hline
\end{tabular}

\section{FTIR spectra}

To elucidate the structure of lignin, and to investigate the differences in the structure of the MWL and dioxane lignin isolated from Nalita and aspen wood, FT-IR spectra were recorded and shown in Fig. 2. All spectra are showing absorbance near $1330 \mathrm{~cm}^{-1}$ (syringyl), which is typical for
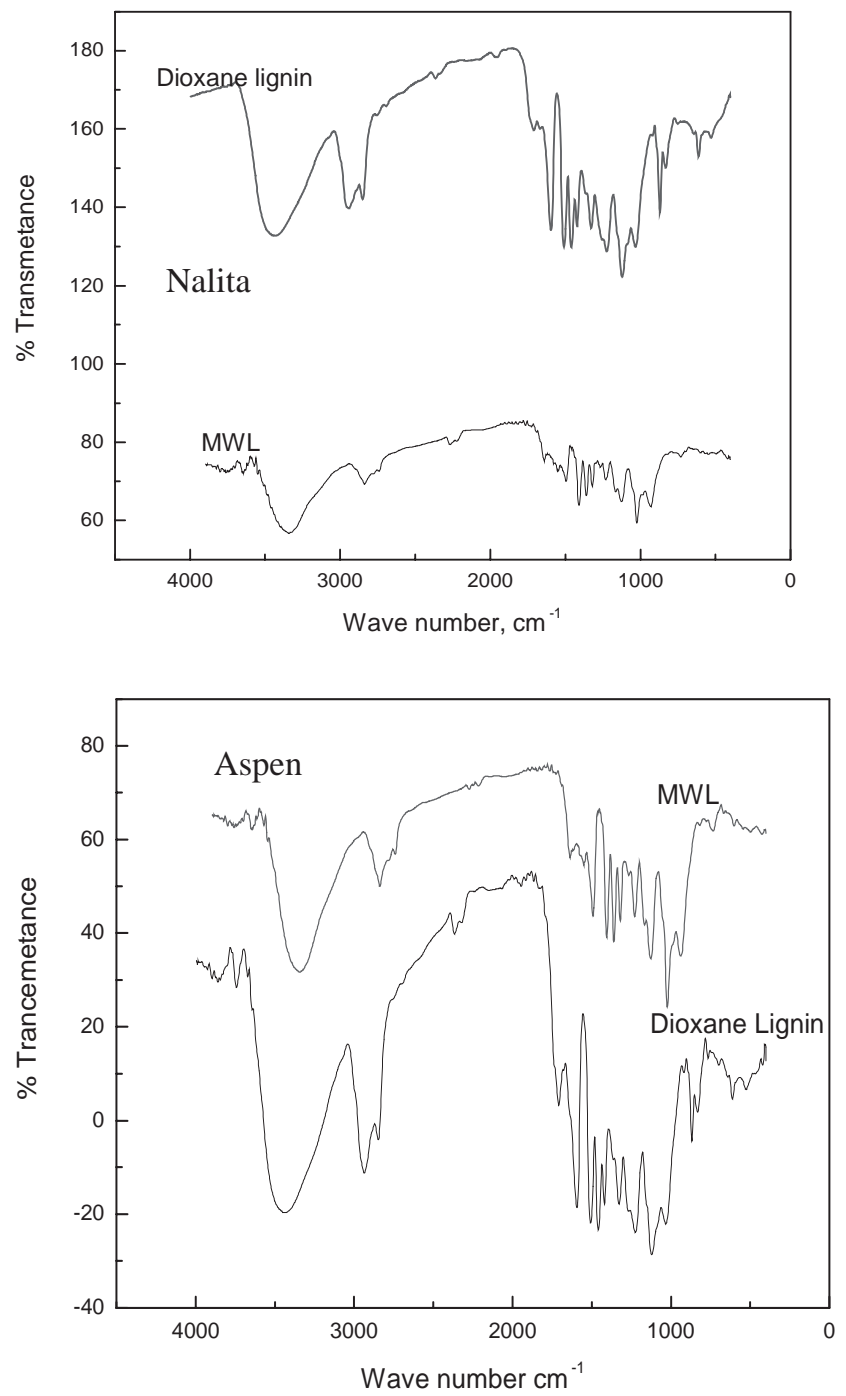

Fig. 2. FT-IR spectra of MWL and dioxane lignin from Nalita and Aspen hardwood lignin and shoulder at $1270 \mathrm{~cm}^{-1}$ (guaiacyl) (Faix 1991). Further evidence of the syringyl content in Nalita and aspen lignin is afforded by its having a band near $835 \mathrm{~cm}^{-1}$ but no band at 855 or $815 \mathrm{~cm}^{-1}$, later two guaiacyl bands are typical for softwood lignin not exhibited by hardwoods (Obst 1982). The $\mathrm{C}=\mathrm{O}$ in unconjugated ketone ( $\beta$-carbonyl) were observed in all spectra at $1710 \mathrm{~cm}^{-1}$, but the intensity of this band was lower in Nalita lignin than aspen lignin (Lora and Wayman 1980). Aromatic vibration in the lignin fraction are assigned at 1595, 1510, $1421 \mathrm{~cm}^{-1}$. The band at 1460 $\mathrm{cm}^{-1}$ indicates the $\mathrm{C}-\mathrm{H}$ deformation and aromatic ring vibrations. The strong intensities of the band at 1329 and 1122 $\mathrm{cm}^{-1}$ are associated with syringyl structure in the lignin molecule. The bands at 1225, 1034 and shoulder at $1156 \mathrm{~cm}^{-1}$ are associated with guaiacyl units in lignin molecules, which indicated the presence of both guaciyl and syringyl unit in the lignin molecule.

\section{Elemental and methoxyl analysis}

Table III summarizes the results from $\mathrm{C}, \mathrm{H}, \mathrm{N}, \mathrm{O}$ and methoxyl analyses of Nalita and aspen MWL and dioxane lignin. The elemental results were corrected on the basis of the presence 3 and $5 \%$ xylan content in MWL and dioxane lignin, respectively. The values obtained were within the accepted ranges for hardwoods. The number of methoxyl group per $\mathrm{C}_{9}$ of Nalita MWL was 1.36 and dioxane lignin 1.27 while aspen MWL was 1.52 and dioxane lignin 1.47. Temperate hardwood lignin contains more syringyl lignin than tropical hardwood lignin. So aspen (temperate hardwood) showed higher methoxyl than Nalita (tropical hardwood) in both isolation methods. MWL showed a higher methoxyl than dioxane in both species. It is known that the secondary wall of hardwood lignin is enriched in syringyl units (Chang et al. 1975). Therefore, variation in $\mathrm{OCH}_{3}$ per $\mathrm{C}_{9}$ in MWL and dioxane lignin may also be associated with secondary wall lignin. $\mathrm{O} / \mathrm{C}_{9}$ unit was higher than 3 in all lignins. A value of $\mathrm{O} / \mathrm{C}_{9}$ higher than 3 have been observed in the lignin of the genus Populus (Lora and Wayman 1980; Sarkanen et al. 1967), and was consistent with the presence of aromatic esters, which is shown in IR spectroscopy. 
Table III. Elemental analyses, methoxyl contents and per- $\mathrm{C}_{9}$-unit formula of Nalita and Aspen lignin.

\begin{tabular}{l|c|c|c|c|c|c}
\hline \multirow{2}{*}{$\begin{array}{l}\text { Lignin } \\
\text { sample }\end{array}$} & \multicolumn{3}{|c|}{ Elemental analysis, \% } & \multirow{2}{*}{$\mathrm{C}_{9}$ formula* } \\
\cline { 2 - 6 } & $\mathrm{C}$ & $\mathrm{H}$ & $\mathrm{N}$ & $\mathrm{O}$ & $\mathrm{OCH}_{3}$ & \\
\hline Nalita & & & & & \\
MWL & 56.97 & 5.89 & 0.11 & 37.03 & 19.11 & $\mathrm{C}_{9} \mathrm{H}_{9.11} \mathrm{O}_{3.97}\left(\mathrm{OCH}_{3}\right)_{1.36}$ \\
Dioxane & 59.04 & 6.29 & 0.06 & 34.61 & 19.01 & $\mathrm{C}_{9} \mathrm{H}_{9.31} \mathrm{O}_{3.13}\left(\mathrm{OCH}_{3}\right)_{1.27}$ \\
Aspen & & & & & & \\
MWL & 55.65 & 5.95 & 0.09 & 38.31 & 20.81 & $\mathrm{C}_{9} \mathrm{H}_{8.93} \mathrm{O}_{3.50}\left(\mathrm{OCH}_{3}\right)_{1.52}$ \\
Dioxane & 58.93 & 6.01 & 0.05 & 34.78 & 20.74 & $\mathrm{C}_{9} \mathrm{H}_{8.94} \mathrm{O}_{3.15}\left(\mathrm{OCH}_{3}\right)_{1.47}$ \\
\hline
\end{tabular}

*Empirical analyses formula $\mathrm{C}_{\mathrm{X}} \mathrm{H}_{\mathrm{Y}} \mathrm{O}_{\mathrm{Z}}\left(\mathrm{OCH}_{3}\right)_{\mathrm{n}}$, were calculated as follows: $\mathrm{n}=\left(\% \mathrm{OCH}_{3}\right) / 31.04 ; \mathrm{x}=(\% \mathrm{C}) / 12-\mathrm{n}$; $\mathrm{y}=(\% \mathrm{H})-3 \mathrm{n} ; \mathrm{z}=(\% \mathrm{O}) / 16-\mathrm{n}$

\section{Alkaline nitrobenzene oxidation}

Table IV shows the yield of alkaline nitrobenzene oxidation products of Nalita and aspen MWL and dioxane lignin. It is seen that the predominant product was identified to be syringaldehyde (S) followed by vanillin (V). Aspen lignin (31-32 \%) had more syringadehyde than Nalita lignin (21-24 $\%)$. It was resulted from the degradation of noncondensed syringyl unit and guaiacyl unit. Total aldehyde yield of Nalita wood lignin was 35-39 \%, while it was 41-42 \% for aspen lignin. The total yield of nitrobenzene oxidation products is lower than the yield reported for other hardwoods (42-50 \%) (Chen 1992). This fact reflects a high abundance of condensed structure in Nalita lignin. Aspen lignin contains less condensed structure than Nalita lignin. The relative molar ratio of $\mathrm{S}$ to $\mathrm{V}$ was appeared to 1.7-1.8 for Nalita lignin and 3.0-3.1 for aspen wood lignin. The S/V ratio of temperate hardwood is higher than that of tropical hardwood as reported elsewhere (Sarkanen and Hergert 1971). The results appeared to be in general agreement with the range of $\mathrm{S}$ to $\mathrm{V}$ ratios obtained from hardwood lignin (Creighton et al. 1944). A minor amount of $p$-hydroxyphenyl unit was also present in Nalita wood lignin (2.7-2.8 \%). This result is consistent with the UV spectra. The differences of results of alkaline nitrobenzene oxidation in isolation method were minor.

\section{Molecular weight}

The weight average (Mw) and number-average (Mn) molecular weight, and polydispersity of Nalita and aspen MWL and dioxane lignin are shown in Table V. The data shows that the weight average molecular weight $(\mathrm{Mw})$ of Nalita lignin was higher than aspen lignin. Previous study showed that the Mw decreased with tree age of Nalita (Jahan and Mun 2007). Mw of Nalita MWL was also higher than the dioxane lignin (Table V). The molecular weight of spruce MWL decreased with increasing milling time (Chang et al. 1975). The highest Mw reported for analytical lignins are 77,000 for an enzymatically isolated MWL of Eastern hemlock (Tsuga Canadensis), and 85,000 for a dioxane spruce lignin fraction (Fengel and Wegener 1984). The molecular weight of MWL also depends on milling conditions.

\section{${ }^{1}$ H NMR}

The integrated NMR spectrum obtained for acetylated Nalita and aspen MWL and dioxane lignin samples are shown in Figure 3, and Table VI lists the position of signal assigned by Lundquist (Lundquist 1979).

Hydroxyl group: The number of free aliphatic and phenolic hydroxyl groups per $\mathrm{C}_{9}$ units was determined from the cor-

Table IV. The yield of alkaline nitrobenzene oxidation products from Nalita and aspen wood and MWLs

\begin{tabular}{|c|c|c|c|c|c|c|c|c|}
\hline \multirow{3}{*}{$\begin{array}{l}\text { Age of } \\
\text { tree, month }\end{array}$} & \multicolumn{8}{|c|}{ Aldehyde, \% } \\
\hline & \multicolumn{2}{|c|}{$\mathrm{P}$} & \multicolumn{2}{|c|}{$\mathrm{V}$} & \multicolumn{2}{|c|}{ S } & \multicolumn{2}{|c|}{ S/V (molar ratio) } \\
\hline & MWL & Dioxane & MWL & Dioxane & MWL & Dioxane & MWL & Dioxane \\
\hline Nalita & 2.7 & 2.8 & 12,9 & 11.8 & 23.7 & 20.7 & 1.8 & 1.7 \\
\hline Aspen & 0.3 & 0.2 & 10.5 & 10.1 & 31.9 & 30.9 & 3.0 & 3.1 \\
\hline
\end{tabular}

$\mathrm{P}=p$-hydroxy benzaldehyde, $\mathrm{V}=$ vanillin, $\mathrm{S}=$ syringyldehyde. 
Table V. The weight-average (Mw) and number average (Mn) molecular weight and polydispersity (Mw/Mn) of MWLs isolated from Nalita and Aspen wood.

\begin{tabular}{l|c|c|c|c|c|c}
\hline Sample & \multicolumn{2}{|c|}{ Mw } & \multicolumn{2}{c|}{ Mn } & \multicolumn{2}{c}{ Mw/Mn } \\
\cline { 2 - 7 } & MWL & Dioxane & MWL & Dioxane & MWL & Dioxane \\
\cline { 2 - 7 } Nalita & 41,628 & 25,491 & 7,772 & 3,708 & 5.4 & 6.9 \\
Aspen & 23,295 & 20,587 & 4,454 & 3,651 & 5.2 & 5.6 \\
\hline
\end{tabular}

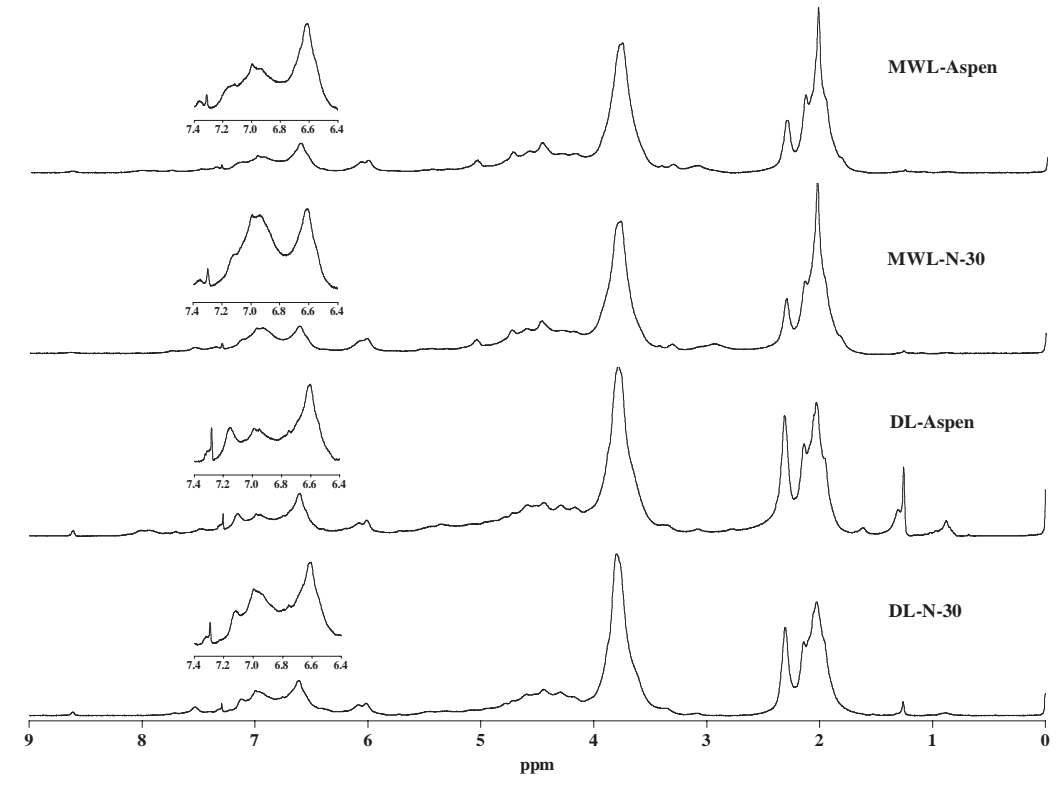

Fig. 3. ${ }^{1} \mathrm{H}$-NMR spectra of MWL and dioxane lignin isolated from Nalita and Aspen

responding acetate signals. The proton of phenolic hydroxyl group of Nalita was 0.23 for MWL and 0.35 per $\mathrm{C}_{9}$ for dioxane lignin, while it was 0.28 and 0.47 per $\mathrm{C}_{9}$ for aspen, respectively. The content of phenolic hydroxyl in dioxane lignin was much higher than that found for the corresponding MWL. This result indicates the formation of new $\mathrm{OH}$ phenolic hydroxyl group during isolation of dioxane lignin by cleavage of interunit linkages (Seca et al. 1998). Similar result was observed in Eucalyptus globules lignin (Evtuguin et al. 2001). Lower phenolic hydroxyl in Nalita lignin may explain the lower reactivity of Nalita lignin as compared to aspen lignin in an alkaline pulping. The proton of aliphatic hydroxyl group was $0.95-1.07 / \mathrm{C}_{9}$ for Nalita and $1.11 / \mathrm{C}_{9}$ for aspen. These results were consistent with Mw data (Table $\mathrm{V})$. In both the species dioxane lignin showed higher hydroxyl group than MWL.
Aromatic protons: Aspen and Nalita MWL and dioxane lignins spectra show two peaks in the aromatic proton region, which correspond to guaiacyl units $(\delta$ 6.9) and syringyl units $(\delta$ 6.6). Aspen lignin shows stronger peak in syringyl units region $(\delta$ 6.6) than guaiacyl units region $(\delta$ 6.9). NMR integration suggests that Nalita lignin had $0.84+$ $0.91=1.75$ aromatic protons for dioxane and $1.02+0.81=$ 1.83 protons per $\mathrm{C}_{9}$ units, while the corresponding aromatic protons in the aspen lignin were $0.44+1.02=1.46$ and 0.79 $+0.91=1.70$, respectively. From analytical composition, considering $100 \mathrm{C}_{9}$ units and their methoxyl contents, the proportion of the syringyl and guaiacyl units was calculated to be 36 and $64 \%$ for MWL and 27 and $73 \%$ for dioxane lignin from Nalita. Aspen lignin showed 47-48 \% syringyl units and 52-53\% guaiacyl units. 
TableVI. Assignments of signals and protons per $\mathrm{C}_{9}$ structural unit in the ${ }^{1} \mathrm{H}$ NMR spectra of acetylated MWL and Dioxane lignin of Nalita and aspen wood.

\begin{tabular}{|c|c|c|c|c|c|}
\hline \multirow[t]{3}{*}{ Range ppm } & \multirow[t]{3}{*}{ Main assignments } & \multicolumn{4}{|c|}{ Proton per $\mathrm{C}_{9}$ unit } \\
\hline & & \multicolumn{2}{|c|}{ Nalita } & \multicolumn{2}{|c|}{ Aspen } \\
\hline & & MWL & Dioxane & MWL & Dioxane \\
\hline $7.25-6.80$ & Aromatic proton in guaiacyl units & 1.02 & 0.84 & 0.79 & 0.44 \\
\hline $6.80-6.25$ & Aromatic proton in syringyl units & 0.81 & 0.91 & 0.91 & 1.02 \\
\hline $6.25-5.75$ & $\mathrm{H} \alpha$ of $\beta-\mathrm{O}-4$ and $\beta-1$ structures & 0.35 & 0.24 & 0.33 & 0.27 \\
\hline $5.75-5.24$ & H $\alpha$ of $\beta-5$ structure & 0.10 & 0.17 & 0.11 & 0.25 \\
\hline $5.20-4.90$ & $\mathrm{H}$ of xylan residue & 0.24 & 0.20 & 0.31 & 0.28 \\
\hline $4.90-4.30$ & $\mathrm{H} \alpha$ \& $\mathrm{H} \beta$ of $\beta-\mathrm{O}-4$ structures & 1.53 & 1.26 & 1.67 & 1.47 \\
\hline $4.30-4.00$ & $\begin{array}{l}\text { H } \alpha \text { of } \beta-\beta \text { structures } \\
\mathrm{H} \text { of xylan residue }\end{array}$ & 0.76 & 0.68 & 0.82 & 0.81 \\
\hline $4.00-3.48$ & $\mathrm{H}$ of methoxyl groups & 4.08 & 3.81 & 4.56 & 4.41 \\
\hline $2.50-2.22$ & $\mathrm{H}$ of aromatic acetates & 0.70 & 1.04 & 0.84 & 1.40 \\
\hline $2.22-1.60$ & H of aliphatic acetates & 4.00 & 2.85 & 4.15 & 3.34 \\
\hline
\end{tabular}

$\beta-O-4$ structure: The aryl glycerol $\beta-\mathrm{O}-4$ aryl ether linkage constitutes the main intermonomeric connection in lignin (Lundquist 1979). NMR spectra of Nalita and aspen lignins show that the structural element may contain both erythro and threo configurations due to the presence of proton at the C- $\alpha$ position of the side chain. The erythro protons $(\mathrm{H} \alpha)$ give stronger peak at $6.01 \mathrm{ppm}$ than the corresponding peak for thero form at $\delta 6.09$ in both Nalita and aspen lignins. The proton of the $C-\beta$ and $C-\gamma$ gave a peak at 4.6 , according to Lundquist et al. (1986) and corresponded to 1.53 and $1.26 / \mathrm{C}_{9}$ protons for Nalita and 1.67 and $1.47 / \mathrm{C}_{9}$ for aspen MWL and dioxane lignin, respectively. Dioxne lignin showed lower that was consistent with phenolic data.

$\beta-5$ and $\beta-\beta$ structures: The proportion of phenylcumarane configurations in Nalita lignin was estimated to be 0.10 and 0.17 per $C_{9}$ unit and aspen lignin was 0.11 and 0.25 for

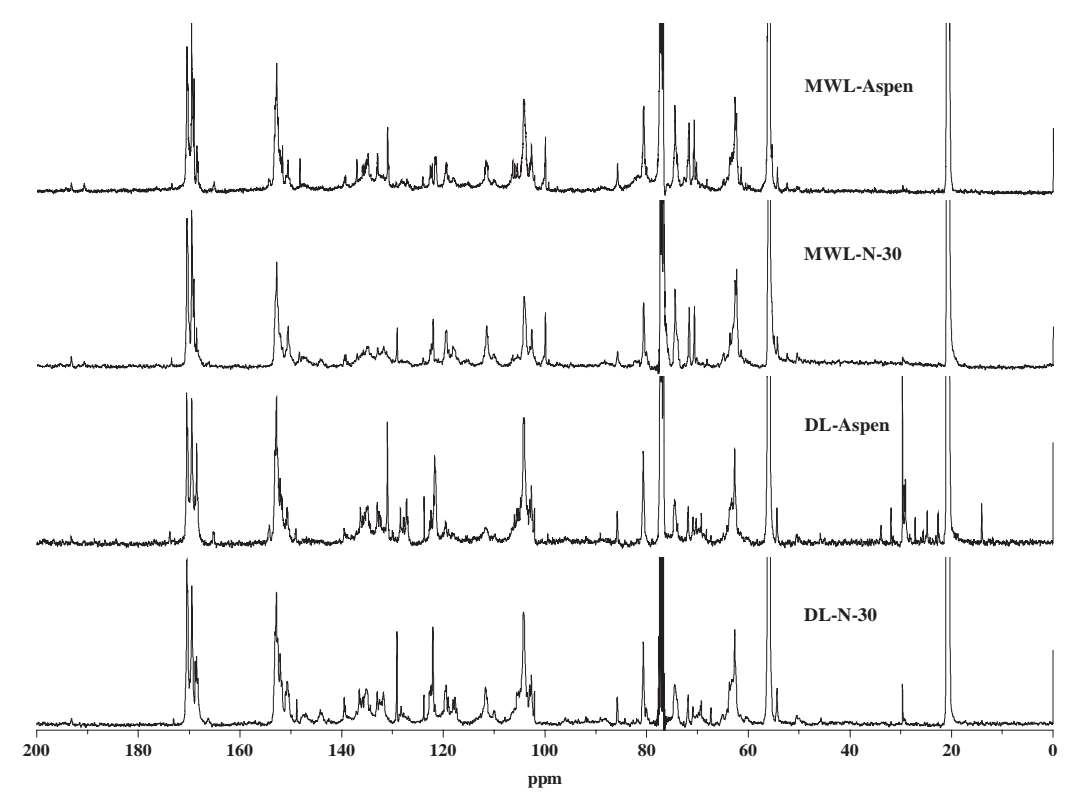

Fig. $4 .{ }^{13} \mathrm{C}-\mathrm{NMR}$ spectra of MWL and dioxane lignin isolated from Nalita and Aspen 
MWL and dioxane lignin, respectively. In both species, dioxane method showed higher proton.

\section{${ }^{13}$ C NMR}

The ${ }^{13} \mathrm{C}$ NMR spectra of acetylated Nalita and aspen lignins are shown in Fig. 4. Since the ${ }^{13} \mathrm{C}$ NMR spectra were recorded under conditions that did not allow quantification, they provide only limited information. The Nalita and aspen lignin had sharp signals in both the aromatic and aliphatic regions. For hardwood lignin the most intense signals in this region are C3/ C5 and C2/C6 at 152.8 and 104.2 ppm, respectively of syringyl units and their appearance in both Nalita and aspen dioxane lignins confirmed GS type (Nimz et al 1981). Similar results were reported in eucalyptus lignin (Vazquez et al 1997). The moderately strong signal at 111.4 and 104.2 ppm in Nalita lignin as compared to aspen lignin confirmed that Nalita lignin contain more guaiacyl lignin than aspen lignin. This result was also confirmed by ${ }^{1} \mathrm{H}-\mathrm{NMR}$ and alkaline nitrobenzene oxidation. The signal at 170.5, 169.6 and 168.5 ppm generated by acetyl carbonyl carbon atom in primary aliphatic, secondary aliphatic and aromatic acetates, respectively, and their relative intensities reflected approximately the concentrations of primary hydroxyl, secondary hydroxyl and phenolic hydroxyl in the dioxane lignin. The relative intensity at 168.5 ppm was much smaller in Nalita dioxane lignin than aspen dioxane lignin, which suggested a lower free phenolic hydroxyl group in Nalita lignins. Red beech had smaller relative intensity than softwood lignin at 168.5 ppm as found by Nimz et al (1976). The signal at 121.3-122.0 ppm indicates the presence of phydroxyphenyl group in Nalita and aspen dioxane lignin. Nimz et al (1981) identified p-hydroxyphenyl group in the compression wood at $\delta 128.5$ and $121.7 \mathrm{ppm}$. The signal at $\delta$ 80.6, 74.5 and 62.7 can be assigned to carbon atom $\beta$, $\alpha$ and $\gamma$ in $\beta-\mathrm{O}-4$ structure, respectively (Nimz et al 1981). Nalita lignin showed stronger intensity for $\mathrm{C} \gamma$ in $\beta-\mathrm{O}-4$ than aspen dioxane lignin.

\section{Conclusion}

The following conclusion may be drawn from this investigation:

- Lignin yield from Nalita was lower than that of aspen in MWL method. Dioxane method showed higher lignin yield.
- $\quad$ The UV spectra showed absorption maxima at $280 \mathrm{~nm}$ for Nalita lignin and $274 \mathrm{~nm}$ for aspen lignin, which indicated higher guaiacyl unit in Nalita than that of aspen lignin.

- The $\mathrm{OCH}_{3} / \mathrm{C}_{9} \mathrm{MWL}$ and dioxane lignin were 1.36 and 1.27 for Nalita, while that of aspen was 1.47 and 1.52, respectively. The molar ratio of syringyldehyde to vanillin in Nalita lignin was lower than that of aspen lignin. Presence of $p$-hydroxyphenyl unit in Nalita lignin was observed.

- The weight average molecular weight (Mw) of Nalita lignin was higher than aspen lignin.

- Lignin obtained by dioxane method was higher in phenolic hydroxyl and lower in $\beta-\mathrm{O}-4$ linkage than MWL.

\section{References}

Adler E. (1977) Lignin chemistry- past, present and future. Wood Sci.Technol., 11: 169-218.

Björkman A. (1954) Isolation of lignin from finely divided wood with neutral solvents. Nature 174:1057-1058.

Boerjan W., Ralph J. and Baucher M. (2003) Lignin biosynthesis. Annu. Rev. Plant Biol. 54: 519-546.

Chang H-M., Cowling E. B., Brown W., Adler E. and Miksche G. E, (1975) Holzforschnung 29(5): 153159.

Chen C. L. (1992) Nitrobenzene and Cupric oxide oxidations. In Methods in lignin Chemistry, Lin, S.Y. Dence, C.W. Eds.: Springer-Verlag, Berlin, pp 301319.

Creighton R. H. J., Gibbs R. B. and Hibbert H. ( 1944) Studies on lignin and related compounds LXXV: Alkaline nitrobenzene oxidation of plant materials and application to Taxonomic Classification. J. Amer. Chem. Soc.66: 32-37.

Evtuguin D. V., Neto C. P.. Silva A. M. S., Domingues P. M., Amado F. M. L., Robert D. and Faix O. (2001) Comprehensive study on the chemical structure of dioxane lignin from plantation Eucalyptus globules wood. J. Agric. Food Chem. 49: 4252-4261. 
Fugimoto A., Matsumoto Y., Chang H. and Meshitsuka G. (2005) Quantitative evaluation of milling effects on lignin structure during the isolation process of milled wood lignin. J. Wood Sci. 51: 89-91.

Faix O. (1991) Classification of lignins from different botanical origins by FT-IR spectroscopy. Holzforschung 45: (suppl): 21-27.

Fengel D. and Wegener G. (1984) Wood: Chemistry, Ultrastructure, Reaction. Walta de Gruyter, Berlin p155

Goldschmid O. (1971). Ultraviolet Spectra In: Sarkaned, K. V. and C. H. Ludwig, Lignins: Occurrence, formation, structure and reactions. Wiley Interscience, New York, 241-266

Gellerstedt G., Pranda J. and Lindfors E.-L. (1994) Structural and molecular properties of residual birch kraft lignins. J. Wood Chem. Technol. 14(4): 467-482.

Guerra A, Filpponen I., Lucia L. A.. and Argyropoulos D. S. (2006) Comparative Evaluation of Three Lignin Isolation Protocols for Various Wood Species. J. Agric. Food Chem. 54: 9696-9705

Higuchi, T., Ito Y., Shimada M. and Kawamura I. (1967) Chemical properties of milled wood lignin of grasses. Phytochemistry 6(11): 1551-1556

Hu Z., Yeh T., Chang H., Matsumoto Y. and Kadla J. (2006) Elucidation of the structure of cellulolytic enzyme lignin. Holzforschung 60: 389-397.

Ikeda T., Holtman K., Kadla J., Chang H. and Jameel H. (2002) Studies on the effect of ball milling on lignin structure using a modified DFRC method. J. Agric. Food Chem. 50: 129-135.

Jahan M. S. and Mun S. P. (2003). Characterization of Nalita Wood (Trema orientalis) as a Source of Fiber for Papermaking (Part I): Anatomical, morphological and chemical properties. Korea Tappi J. 35 (5): 72-79.
Jahan M. S. and Mun S. P. (2004) Effect of tree age on the soda-anthraquinone pulping of Nalita wood (Trema orientalis). Korean J. Ind. Engg. Chem. 10(5): 766771.

Jahan M. S. and Mun S. P. (2006) Characteristics of milled wood lignins isolated from different ages of nalita wood (Trema orientalis). Cellulose Chemistry and Technology 40(6): 457-467.

Jahan M. S. and Mun S. P. (2007) Characteristics of Dioxane Lignins Isolated at Different Ages of Nalita Wood (Trema orientalis). J. of Wood Chemistry and Technology 27(2): 83-98.

Lora J. H. and Wayman M. (1980 ) Autohydrolysis of aspen lignin milled wood lignin. Can J. Chem. 58: 669-676.

Lundquist K. (1979) NMR studies of lignins. 2. Interpretation of the proton NMR spectrum of acetylated birch lignin. Lundquist, Knut. Acta Chemica Scandinavica, Series B: Organic Chemistry and Biochemistry B33(1): 27-30.

Lundquist K. (1976) Low molecular weight lignin hydrolysis products. Proc. Appl.Polym. Symp. John Wiley \& Sons, Inc. New York, NY. USA 1393-1407.

Lundquist K. and Von Unge S. (1986) NMR studies of lignins. 8. Examination of pyridine- $\mathrm{d} 5$ solution of acetylated lignin from Birch and and Spruce by ${ }^{1} \mathrm{H}$ NMR spectroscopy. Acta Chem Scan. B 40: 791-797.

Mun S. P. and Wi H. (1991) Alcohol- Bisulphite cooking of Hyun-Aspan wood- characterization of carbohydrates and lignin in the spent liquor. Korea Tappi J. 23(4): 25-32.

Nimz H. H., Robert D., Faix O. and Nemr M. (1981) Carbon ${ }^{13}$ NMR spectra of lignins, 8. Structral differences between lignin of hardwood, softwood, grasses and compression wood. Holzforschung 35: 16-26.

Nimz H. and Ludemann H. D., (1976) Kohlenstoff-13-NMR Spektren von Ligninen,6. Lignin und DHP-Acetate. Holzforschung, 30: 33-40. 
Obst J. R. (1982) Guaiacyl and syringyl lignin composition in hardwood cell components. Holzforschung 36: 143-152

Sarkanen K. V., Chang H. and Allan G. G. (1967) Species variations in lignins. II. Conifer lignins. III. Hardwood lignins. Tappi 50: 583-590

Sarkanen K. V. and Hergert H. L. (1971) Classification and Distribution. In: Lignins; Occurrence, formation, structure and reactions. Eds Sarkanen K. V. and Ludwid C. H. Wiley-interscience New York p 71
Ralph J., Lundquist K., Brunow G., Lu F., Kim H., Schatz P. F., Marita J. M., Hatfield R. D., Ralph S. A., Christensen J. H. and Boerjan W. (2004) Lignins: natural polymers from oxidative coupling of 4-hydroxyphenylpropanoids. Phytochem. Rev. 3: 29-60.

Vazquez G., Antorrena, G., Gonzalez, J. and Freire, S. (1997) FTIR ${ }^{1} \mathrm{H}$ and ${ }^{13} \mathrm{C}$ NMR Characterization of acetosolvSolubilized Pine and Eucalyptus Lignins Holzforschung 51 (2): 158-166.

Wu S. and Argyropoulos D. S. (2003) An improved method for isolating lignin in high yield and purity. J. Pulp Pap. Sci. 29: 235-240.

Received : August, 26, 2008;

Accepted : May 12, 2009 